\begin{tabular}{|c|c|c|c|}
\hline$\Omega$ & (1] & $\equiv$ & 라 \\
\hline \multirow[t]{4}{*}{ James Y. Paton } & $\begin{array}{l}\text { School of Medicine, } \\
\text { College of Medical, } \\
\text { Veterinary, and Life } \\
\text { Sciences, }\end{array}$ & $\begin{array}{l}\text { Royal Hospital for Sick } \\
\text { Children, Dalnair Street, } \\
\text { Yorkhill, Glasgow, G3 } \\
\text { 8SJ, UK }\end{array}$ & james.paton@glasgow.ac.uk \\
\hline & University of Glasgow, & & \\
\hline & Glasgow, & & \\
\hline & UK & & \\
\hline
\end{tabular}

\title{
Breathe has a new Chief Editor
}

2012 has been the year of the Games of the XXX Olympiad with more than 10,000 athletes from 204 countries competing in London. One of the highlights of the memorable summerwas themen's $4 \times 100$ metre relay competition in which Usain Bolt powered Jamaica to a world-record time of 36.84 seconds, winning his third gold medal of the games.

Most journals run their own slowerversion of a relay race, with the Editors changing every fewyears.

The September issue of Breathe was Prof. Leif Bjermer's last before he passed on the Editorial baton. He leaves Breathe very well placed. At present, each edition of Breathe goes out to $~ 15,000$ subscribers with two-thirds of the readership in Europe and one-third in theUSA and the rest of the world. Testamentto Breathe's wide reach, the website has had visits from 162 countries. Sothejournal has atrulyglobal audience. In aweb survey overthe summer, $70 \%$ ofrespondents were between 25 and 35 years of age with positions across the respiratory spectrum but with a particular concentration in physicians in clinical practice, allied health professionals and trainees. All the Assemblies of the European Respiratory Society (ERS) were represented. Over 95\% of the respondents described Breathe as good or excellent and Reviews, Hot Topic articles and How-To articles were all particularly well received.

As in the Olympic relay, any new editor's first task is not to drop the baton. It is therefore very pleasing and something of a relief to see the December issue out on time with a good range of interesting articles. I am grateful to all the authors for their efforts in providing us with interesting material in good time and for the hard work of the Technical Editors and staff at the European Respiratory Society's publications office in Sheffield, UK.

Of course, every new editor hopes to do at least as well as his predecessors, if not better. Breathe is the educational journal of the ERS and it will continue with its primary mission of providing educational material of the highest possible quality and relevance. As editor of Breathe, I take part in the ERS school meetings and am fortunate to be able to draw on the collective energy, enthusiasmand experience oftheOfficers of the school as an active editorial board. Hopefully, this will keep Breathe well grounded and relevant to its audience.

We plan to continue with a combination of review articles covering all areas of respiratorymedicinewith an emphasis on the important, the topical and the timely. As noted from our survey, Hot Topics and How-To articles are both popular and well regarded and these will remain a regular feature. Case Reports areverymuch loved by clinicians and we will continue to publish those with a clear educational message. Most respiratory professionals cannot resist a challenge, so every issue will have clinical quizzes to stimulate and provoke you. The ERS itself is growing with many new educational activities. We aim to bring the highlights to you with reports from recent ERS courses and Congresses.

There are two areas for which we plan something new. First, ideas and approaches from education are increasingly important in medicine and we aim to bring something of this to you in a regular educational track. Another important area is providing the non-specialist readerwith some understanding of theexciting progress in basic sciences relevant to respiratory medicine. The ERS has, within its memberships, some of the world's finest scientists working in the respiratory field and we are keen to give them a regular platform to write and explain to us about these important developments

Electronic publishing is gradually supplanting paper. In our survey, a quarter ofyou responded thatyou already used the web as your main way of accessing Breathe. One development we expect is that we will gradually be makingmoreuse ofopportunities provided by electronic publishing for example by incorporating other material such as video and photo albums to enrich that material in articles. It is difficult to be surewhat the futurewill look like but it will clearly be different.

As Chief Editor, I would welcome any feedback about how you feel we are doing, good or bad, and any suggestions for topics thatyou thinkshould be covered. Silence is NOT golden! So pleasefeel freeto get in touch.

I hope you continue to find Breathe a good read.
Statement of Interest None declared. 